\title{
Ischaemic stroke-induced distal organ damage: pathophysiology and new therapeutic strategies
}

Chiara Robba ${ }^{1 *}$ (D) Denise Battaglini ${ }^{1,2}$, Cynthia S. Samary ${ }^{3}$, Pedro L. Silva ${ }^{3}$, Lorenzo Ball ${ }^{1,2}$, Patricia R. M. Rocco ${ }^{3}$ and Paolo Pelosi ${ }^{1,2}$

From 4th International Symposium on Acute Pulmonary Injury and Translational Research - INSPIRES 2019

Dresden, Germany. 25-26 November 2019

\footnotetext{
* Correspondence: kiarobba@gmail. com

Anesthesia and Intensive Care, San Martino Policlinico Hospital, IRCCS for Oncology and Neuroscience, Largo Rosanna Benzi 10, 16100 Genoa, Italy

Full list of author information is available at the end of the article
}

\begin{abstract}
Acute ischaemic stroke is associated with a high risk of non-neurological complications, which include respiratory failure, cardiovascular dysfunction, kidney and liver injury, and altered immune and endocrine function. The aim of this manuscript is to provide an overview of the main forms of stroke-induced distal organ damage, providing new pathophysiological insights and recommendations for clinical management.

Non-neurological complications of stroke can affect outcomes, with potential for serious short-term and long-term consequences. Many of these complications can be prevented; when prevention is not feasible, early detection and proper management can still be effective in mitigating their adverse impact. The general care of stroke survivors entails not only treatment in the acute setting but also prevention of secondary complications that might hinder functional recovery. Acute ischaemic stroke triggers a cascade of events-including local and systemic activation of the immune system - which results in a number of systemic consequences and, ultimately, may cause organ failure. Understanding the pathophysiology and clinical relevance of non-neurological complications is a crucial component in the proper treatment of patients with acute stroke.

Little evidence-based data is available to guide management of these complications. There is a clear need for improved surveillance and specific interventions for the prevention, early diagnosis, and proper management of non-neurological complications during the acute phase of ischaemic stroke, which should reduce morbidity and mortality.
\end{abstract}

Keywords: Stroke, Extracranial complications, Cardiac dysfunction, Organs cross talk, Stroke-associated pneumonia 


\section{Background}

The brain controls various body functions through complex neurohumoral mechanisms. Therefore, any severe cerebral insult, such as that which follows an acute ischaemic stroke, can induce several changes in specific neurosensory or neuromotor pathways, enhance the systemic response to local injury, and cause secondary peripheral organ damage [1]. Although the incidence of ischaemic stroke is declining, it remains the second leading cause of death worldwide [2]. Amongst stroke subtypes, ischaemic stroke is the most frequent, though incidence significantly varies across countries [2]. Current research suggests that only $28 \%$ of stroke patients have a favourable outcome (assessed through the modified Rankin scale) at 3 months [3]. The high risk of neurological deterioration and systemic organ dysfunction after stroke often requires intensive care unit admission, consequently increasing hospitalisation costs [4]. Overall, critically ill patients are particularly prone to developing organ dysfunction. The multiple organ dysfunction syndrome (MODS) occurs in up to $14 \%$ of these patients, and accounts for $80 \%$ of intensive care unit deaths [5]. Few studies have reported data on systemic complications after stroke, but the incidence of MODS is estimated at up to $12 \%$ of cases [6] (Figure 1). Low Glasgow Coma Score, advanced age, hypo- and hyperglycaemia, leucocytosis, and a history of chronic disease have been identified as risk factors for MODS after stroke [6]. Although some experimental data on stroke-induced peripheral organ damage and MODS is available, the literature on clinical features of multiorgan failure and its management after stroke is scarce. Therefore, the aim of our manuscript is to describe the prevalence, pathophysiology, features, and treatment of the main types of distal organ damage occurring after acute ischaemic stroke. For this purpose, we searched four electronic databases (PubMED, Scopus, ScienceDirect, Web of Science) for manuscripts describing extracranial complications after acute ischaemic stroke, with no time restriction. Only manuscripts in English were considered; titles and abstracts were retrieved and independently assessed for eligibility by two authors (CR, DB). Disagreements were resolved by discussion and consensus agreement, and, if required, input from a third author (CSS).

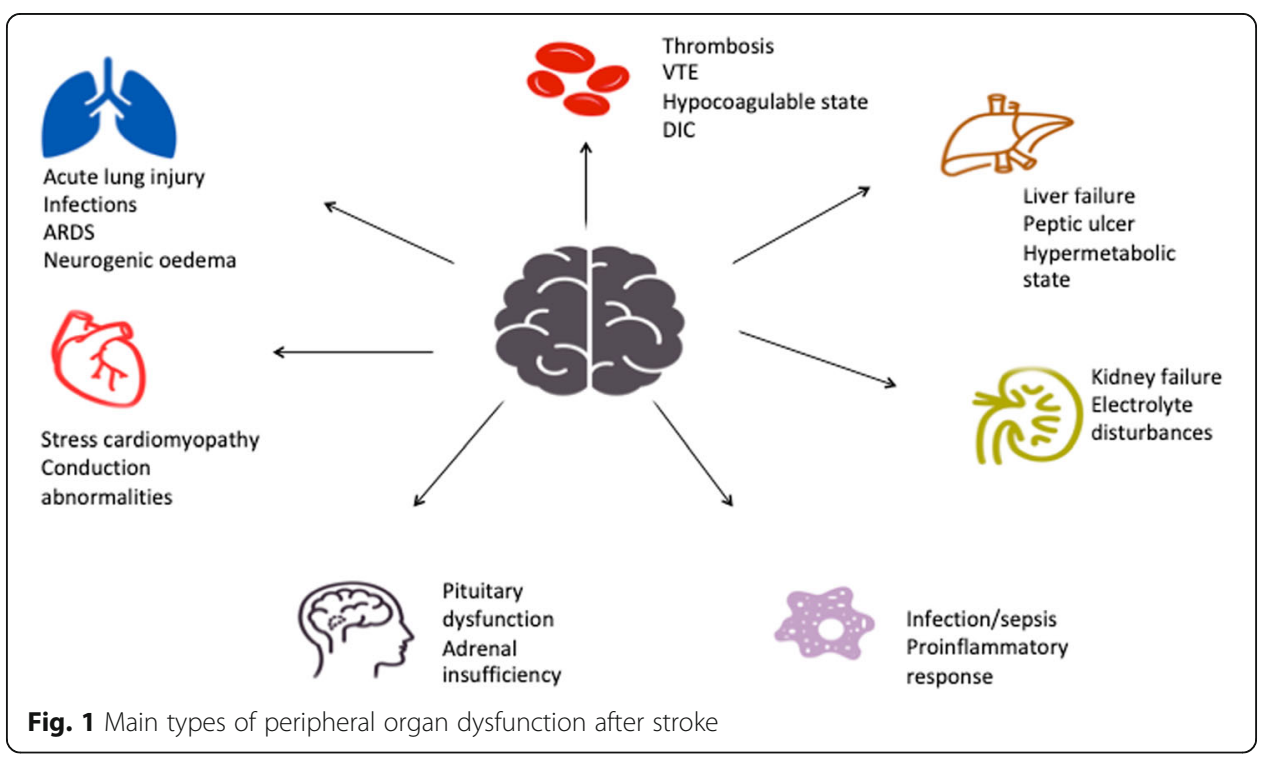




\section{Respiratory complications \\ Brain-lung crosstalk in stroke}

Data suggest that pulmonary complications are common and occur early after stroke, are common causes of intensive care unit admission, and are associated with high mortality and morbidity rates [7]. The lung is particularly susceptible to severe brain damage (such as that which follows ischaemic and haemorrhagic stroke). A recent clinical study found that, $36 \mathrm{~h}$ after hospital admission, $15.6 \%$ of stroke patients had acute lung injury, and 7.8\% developed pneumonia or bronchitis during their hospital stay [8]. Different pathways have been implicated in brain-lung crosstalk after stroke [9]. Experimental stroke models have focused mostly on the role of immune modulation, as local and systemic immune activation is known to predispose to lung injury [10]. Although clinical trials in this particular subpopulation of intensive care unit patients are lacking, the use of protective ventilation strategies and administration of dopamine agonists and antagonists to minimise brain and lung damage has been suggested in experimental settings [10, 11] (Fig. 2).

\section{Acute respiratory distress syndrome and hypoxia}

Among respiratory complications [12, 13], the acute respiratory distress syndrome (ARDS) is a severe pulmonary condition characterised by severe hypoxia and bilateral lung infiltrates [14]. In a large retrospective cohort study of patients with

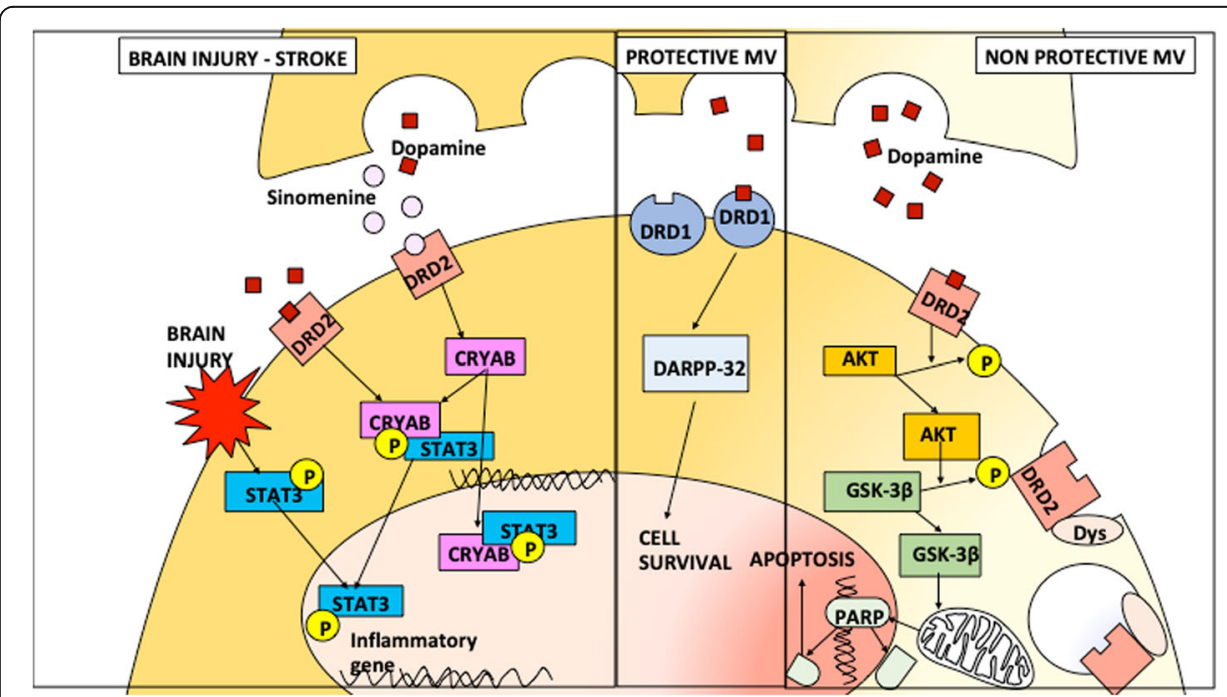

Fig. 2 Mechanisms of immunomodulation and cell apoptosis induced by the dopamine pathway. Under normal conditions, dopamine activates type 1 receptors (DRD1), promoting cell survival. The increased release of dopamine triggered by non-protective mechanical ventilation activates type 2 receptors (DRD2), triggering a cascade of events resulting in apoptosis. Activation of astrocytic DRD2 induces upregulation and nuclear translocation of the aB-crystallin CRYAB/STAT3 pathway, which alleviates neuroinflammatory injury by reducing the generation of pro-inflammatory cytokines. In this context, dopamine agonists and antagonists can play a role in regulating the neuroinflammatory response; in particular, haloperidol—which competitively blocks postsynaptic dopamine receptors in the mesolimbic dopaminergic system-has different effects on cell survival depending on the use of protective and non-protective ventilation. Sinomenine can blunt the CRYAB/STAT3 pathway by acting on DRD2 receptors, thus suppressing neuroinflammation 
acute ischaemic stroke, ARDS prevalence was found to be low (about 4\%), but when it did occur, it had a significant impact on in-hospital mortality [14]. This incidence seems to be lower than in other brain-injured groups; e.g., ARDS occurs in up to $30 \%$ of patients with subarachnoid haemorrhage [15]. A recent experimental study investigated ARDS incidence in stroke and found that focal ischaemic stroke was often followed by acute lung injury, but not by full-blown ARDS [16]. Aspiration of oropharyngeal and gastric content is one of the main causes of ARDS, occurring in up to $3.6 \%$ of stroke patients, and it is associated with swallowing dysfunction, neurologic dysphagia, and gastrointestinal issues [17].

The incidence of ARDS in brain-injured patients is decreasing [18]. Overall, the neurologic population is shifting from one of predominantly traumatic brain injury to one of non-traumatic cerebral haemorrhage and ischaemic stroke, which is likely to influence future clinical, diagnostic, and research practise in health care systems. The main issue in the management of ARDS patients affected by stroke is whether one should apply a protective ventilator strategy but maintain normocapnia (with an arterial partial pressure of carbon dioxide between $35-45 \mathrm{mmHg}$ ) [19]. Indeed, although permissive hypercapnia is commonly used in patients with ARDS, it can have a detrimental effect on cerebral blood flow and intracranial pressure [19]. Current ventilatory strategies to manage ARDS have been investigated in multicentre studies conducted in nonbrain-injured patients; none has focused on stroke patients as a subpopulation. In the general population, evidence suggests the use of low tidal volumes $(6 \mathrm{~mL} / \mathrm{kg}$ predicted body weight $[\mathrm{PBW}])$ to reduce mortality and increase ventilator-free days [20]. Likewise, recruitment manoeuvres (RM) and positive end-expiratory pressure (PEEP) are considered part of any protective ventilation strategy [20], but may increase intrathoracic pressure and impair cerebral perfusion pressure [21].

Hypoxia with arterial oxygen saturation $<90 \%$ in the first hours after hospital admission is associated with a twofold risk of death [22]. However, recent evidence suggests that hyperoxia must be avoided as well, because it is associated with high mortality, delayed cerebral ischaemia, respiratory tract infections, and poor outcomes in braininjured patients [23-25]. A recent meta-analysis showed that hyperoxia may be associated with increased mortality in different groups of patients, including after stroke [24].

No specific recommendations are available for stroke patients with ARDS; maintaining an arterial pressure of oxygen between $60-80 \mathrm{mmHg}$ in both ARDS and braininjured patients is widely accepted [19]. The fraction of inspired oxygen $\left(\mathrm{FiO}_{2}\right)$ should be titrated to achieve the minimal acceptable $\mathrm{O}_{2}$ saturation $\left(\mathrm{SpO}_{2}\right)$ (88-92\%). Driving pressure should be kept $<13 \mathrm{cmH}_{2} \mathrm{O}$, and respiratory rate as low as possible for $\mathrm{pH}>$ $7.25[26]$.

\section{Stroke-associated pneumonia and lower respiratory tract infection}

Pneumonia is one of the most common complications after stroke, largely due to aspiration consequent to the inability of stroke patients to maintain airway patency [27]. However, the incidence of pneumonia after stroke is higher with respect to general (non-stroke) intensive care unit patients who suffer from dysphagia and altered level of consciousness, thus suggesting a role of causative mechanisms other than aspiration, such as abnormal immune patterns and lung dysfunction [28]. Additionally, the 
incidence of stroke-associated pneumonia is higher in intensive care units than in nonintensive stroke wards, ranging from 3.9-56.6\% [29]. Common independent risk factors for aspiration pneumonia in stroke patients were recently investigated in the PREDICT multicentre observational study, which confirmed that both stroke-associated immunodepression and dysphagia can contribute to stroke-associated pneumonia [28]. Although several scores have been proposed for the prediction of stroke-associated pneumonia, their use in clinical practise is uncommon [30]. Biomarkers (such as Creactive protein), stroke severity scores, and dysphagia scores remain most commonly used at bedside [31]. Early mobilisation is strongly recommended, while early antibiotic therapy seems not to improve functional outcome at 3 months in adults with acute ischaemic stroke [32].

\section{Ventilator management in non-ARDS stroke patients}

Both mechanical and neurohumoral inflammatory mechanisms are involved in brainlung crosstalk, enhancing the possible negative effects of mechanical ventilation on specific areas of the brain, even in patients without pre-existing respiratory disease [7]. Although large, multicentre clinical trials on mechanical ventilation settings have often excluded neurologic patients, several experimental studies have investigated this issue. Quilez et al. investigated three different respiratory strategies (mechanical ventilation with different tidal volumes versus spontaneous breathing) in healthy rats, demonstrating the development of significant morphofunctional and biochemical alterations in mechanically ventilated as compared to non-ventilated rats [33]. Additionally, in ventilated rats, the authors observed increased release of inflammatory markers in the lung and plasma, as well as c-fos gene activation in the central amygdala, hippocampus, paraventricular hypothalamic nuclei, and supraoptic nucleus. Rats ventilated with higher tidal volumes also exhibited a heightened inflammatory response, thus suggesting an important role of ventilator-induced lung injury on peripheral organ damage, including in the brain [33]. Furthermore, specific mechanisms have been implicated in lung injury after stroke. Samary et al. conducted an experimental study on rats which demonstrated increased diffuse alveolar damage (especially in endothelial cells and type II pneumocytes), pulmonary oedema, and inflammatory markers in the lungs of stroked rats. A heightened pro-inflammatory response was demonstrated in the brain, lung, plasma (tumour necrosis factor- $\alpha$ and interleukin-6), and bronchoalveolar lavage fluid (tumour necrosis factor- $\alpha$ ) [34]. Moreover, in an experimental study on pigs with haemorrhagic stroke, high PEEP levels $\left(>20 \mathrm{cmH}_{2} \mathrm{O}\right)$ caused impairment of autoregulation with decreased mean arterial pressure, but without impairing intracranial pressure, cerebral oxygenation, or regional cerebral blood flow [35]. Specific pathophysiological mechanisms involved in stroke and the effects of protective versus non-protective mechanical ventilation strategies are summarised in Fig. 2.

Optimal settings for mechanical ventilation in stroke patients without ARDS remain controversial [36]. Protective mechanical ventilation using a tidal volume of $6 \mathrm{~mL} / \mathrm{kg}$ PBW, adequate PEEP levels, plateau pressure $<30 \mathrm{cmH}_{2} \mathrm{O}$, and recruitment manoeuvres (RMs) as needed has been associated with reduced mortality (up to 10\%) in general (non-ARDS) critically ill patients [20]. However, a recent trial of non-ARDS patients ( $8 \%$ affected by brain injury) suggested that low tidal volume strategies $(4-6 \mathrm{~mL} / \mathrm{kg})$ do 
not reduce ventilation-free days when compared to intermediate tidal volume strategies $(8 \mathrm{~mL} / \mathrm{kg})$ [37]. Otherwise, a clinical trial of general brain-injured patients showed an improvement in ventilator-free days in those treated with a protective ventilator strategy (tidal volume of $6-8 \mathrm{ml} / \mathrm{kg}$ of PBW and PEEP $>3 \mathrm{cmH}_{2} \mathrm{O}$ ) [38]. Another multicentre trial which included more than 700 brain-injured patients demonstrated that protective mechanical ventilation (tidal volume $<7 \mathrm{ml} / \mathrm{kg}$ PBW, PEEP $6-8 \mathrm{cmH}_{2} \mathrm{O}$ ) can improve ventilator-free days at day 90 and reduce mortality rate [39]. A recent trial by Mascia et al. demonstrated that the application of PEEP increases intracranial pressure only in patients in whom PEEP causes alveolar hyperinflation and hypercapnia [40], whereas other authors have suggested that PEEP has a detrimental effect on cerebral haemodynamics only if it affects mean arterial pressure and cerebral perfusion pressure [41]. With regard to RMs, no conclusive evidence is available for non-ARDS patients, although these should not be used routinely; no evidence whatsoever is available for brain-injured patients in particular [21]. Taken together, these findings suggest that PEEP and RMs manoeuvres may have a role to play in mechanically ventilated stroke patients, but should only be performed under strict hemodynamic and neurologic monitoring [42]. In the absence of ARDS, we recommend using a protective tidal volume (6-8 mL/kg PBW), which can be increased up to $10 \mathrm{~mL} / \mathrm{kg}$ PBW if needed; Pplat should be kept below $25 \mathrm{cmH}_{2} \mathrm{O}$, and PEEP $5 \mathrm{cmH}_{2} \mathrm{O}$ in patients without ARDS (increased up to $15 \mathrm{cmH}_{2} \mathrm{O}$ if necessary in ARDS).

\section{Cardiovascular complications}

Common knowledge on cerebrovascular and cardiovascular diseases has been changing in recent last decades. Early detection of cardiovascular dysfunction directly caused by stroke, instead of independent cardiovascular illness, has become paramount. Researchers now generally agree on the existence of a bidirectional interaction between the brain and the heart [43].

Corroborating this so-called brain-heart crosstalk theory, stroke patients are extremely vulnerable to the development of severe cardiac complications, possibly due to changes in autonomic and neurohormonal pathways involved in the control of heart function [44]. Our understanding of the pathophysiology of stroke-heart interactions has improved greatly over the past few decades: inflammation and immunity [45], sympathetic hyperactivity [46], the hypothalamic-pituitary-adrenal axis [47], and gut dysbiosis [48] have been identified as the main pathologic factors involved in brain-heart axis dysregulation after both ischaemic and haemorrhagic stroke [46].

\section{Clinical implications}

Data suggest that patients affected by stroke share the same cardiovascular risk factors of those affected by cardiovascular dysfunction [49, 50]. Most critical cardiovascular complications are identified within a few hours of stroke [51,52]. The leading causes of mortality following acute stroke include heart attack [44], congestive heart failure, haemodynamic instability, left ventricular systolic dysfunction [53], diastolic dysfunction, arrhythmias [54], and cardiac arrest [44], which are all associated with delayed cerebral ischaemia, poor outcome, and death. 


\section{Acute cardiac dysfunction}

Acute cardiac dysfunction occurs in up to $67 \%$ of patients with ischaemic stroke [55]. Common manifestations include arrhythmias, electrocardiographic (ECG) changes [49], and acute myocardial infarction-like complications [56].

ECG changes occur in 15 to $30 \%$ of patients with stroke [57-59]. Frequent abnormalities include $\mathrm{T}$ wave inversion, ST elevation, ST depression, upright $\mathrm{T}$ waves, and pathological Q waves $[55,60]$.

Taking into account ischaemic myocardial damage, $50 \%$ of stroke patients without previous cardiac history suffers from coronary stenosis, with a high risk of myocardial infarction within the following 3 years [61]. A meta-analysis including 67,000 patients demonstrated that the annual risk for developing myocardial infarction after stroke is about $2 \%$, followed by a $20 \% 10$-year risk of myocardial ischaemia [60, 62]. A common myocardial infarction-like manifestation is neurogenic stunned myocardium, which differs from traditional myocardial damage because of the absence of coronary artery occlusion [63].

\section{Chronic cardiac dysfunction}

A common consequence of arrhythmic disease and myocardial dysfunction is chronic myocardial remodelling $[64,65]$. An experimental study in stroke mice confirmed the utility of beta blockers to decelerate extracellular cardiac remodelling by modulating sympathetic activity [66].

Diastolic and systolic ventricular dysfunctions are significant post-stroke complications, which affect $15-25 \%$ of patients [67]. Amongst these, in a retrospective cohort, $46 \%$ became functionally dependent or died [68].

\section{Treatment}

Intensive care unit admission with continuous haemodynamic monitoring has been proposed as mandatory for patients with stroke at high risk of developing cardiovascular complications [69], based on the National Institute of Health Stroke Scale (NIHSS) [69]. Suggested haemodynamic monitoring for these patients includes ECG, continuous recording of vital signs, and echocardiography [68, 70, 71]. Some recent trials investigated the potential effect of specific therapies to prevent secondary cerebrovascular and cardiovascular accidents after stroke [72, 73]. Amongst these, drugs such as labetalol, nicardipine, and nitroprusside have been recommended to control hypertension during the acute phase of stroke [72], when systolic blood pressure exceeds 180-200 mmHg, while angiotensin-converting-enzyme inhibitors and angiotensin II receptor blockers are advised for the management of chronic hypertension [73]. A neuroprotective effect of propranolol has been recently demonstrated in experimental settings [11], and beta blockers have been suggested both for preventing chronic remodelling and for treatment of arrhythmias [73]. In addition, any electrolyte imbalances should be taken into account when rhythm abnormalities are treated [72].

In conclusion, therapeutic targets in stroke-related cardiovascular complications remain challenging. Further experimental and clinical investigations are essential to complete this complex multi-disciplinary puzzle. 


\section{Other complications}

\section{Renal complications}

Acute kidney injury (AKI) affects approximately $35 \%$ of patients admitted to intensive care units [74-78]. In a recent meta-analysis, the pooled incidence of AKI was $9.6 \%$ in ischaemic stroke and $19.2 \%$ in haemorrhagic stroke [74]. Risk factors for AKI amongst studies varied significantly, and all authors concluded that AKI after stroke significantly increases mortality rate (OR 2.45) [74].

A large, multicentre study of a cohort of ischaemic stroke patients, 35\% affected by AKI, found that AKI occurrence was associated with a higher risk of neurological deterioration and in-hospital mortality (138\% greater) [79]. In addition, the risk of cardioembolic stroke was greatly increased in patients with AKI, as was the risk for recurrence, of which albuminuria was an independent predictor [80]. Albuminuria was also found to be a predictor of haemorrhagic transformation of ischaemic stroke [81]. Creatinine levels, in turn, were associated with large baseline hematoma volume [82], death, and severe disability [83] at 1 year.

\section{Hepatic complications}

Following acute ischaemic stroke, glucose metabolism, and proteins implicated in insulin and growth hormone signalling in the liver are altered. Stroke-induced liver injury and hepatocyte dysfunction are associated with metabolic derangements, a decrease in hepatic transcription factors, and impaired host immune function, protein synthesis, and clearance of activated clotting factors [84]. Liver failure is an important risk factor for cardiovascular disease, but its association with cerebrovascular diseases such as ischaemic and haemorrhagic stroke is still poorly investigated [84]. In a recent study, approximately $61 \%$ of patients with no history of previous hepatobiliary dysfunction had abnormal hepatic enzyme levels at general intensive-care unit admission, and this finding was associated with increased short-term mortality.

The prevalence of hypoxic hepatitis is estimated at $1-12 \%$ in general critically ill patients [85]. Hypoxic hepatitis is a common consequence of cardiovascular insults due to inadequate oxygen delivery to distal organs, causing a tenfold elevation of aspartate aminotransferase, rise in international normalised ratio, and impaired renal function [85]. However, its association with stroke has not been studied to date [85].

\section{Endocrine complications}

Current evidence suggests that anterior pituitary deficiency occurs in $19 \%$ of patients after ischaemic stroke [86]. A prospective, single-centre trial investigating hypopituitarism after stroke suggested that its incidence increases over time, and is associated with impaired functional outcome [86]. The same authors conducted another study to assess the risk of outcome severity in stroke patients with growth hormone and insulin-like growth factor-1 dysfunction [87]. Approximately $12 \%$ of patients exhibited growth hormone deficiency, while comparatively few developed hypogonadisms. Insulin-like growth factor and growth hormone levels showed a strong association with functional and neurocognitive outcomes [87].

Amongst anterior pituitary dysfunctions, adrenal insufficiency seems to be the most common, and has been identified in $31 \%$ of stroke patients [88]. However, the effect of 
adrenal insufficiency on outcome is not clear [88]. Posterior pituitary dysfunctioncharacterised by inappropriate secretion of antidiuretic hormone and cerebral salt wasting-is common after stroke. The cornerstones of treatment for cerebral salt wasting are fluid replacement and sodium administration; conversely, inappropriate secretion of antidiuretic hormone must be treated with fluid restriction. Hence, distinguishing the two and making the correct diagnosis is paramount to allow prompt initiation of proper treatment.

\section{Conclusions}

Peripheral-organ dysfunctions are particularly common after ischaemic stroke, and their prevention and treatment usually require specific interventions. Knowledge of the nature and timing of systemic complications after acute ischaemic stroke, alongside the identification of high-risk patients, may be useful to allow prompt, early management of these patients and improve their outcomes. The most common complications after stroke include respiratory failure and cardiovascular dysfunction. Most peripheralorgan damage arises within the first week after stroke; however, there is little data to guide the management of these complications. Additional, carefully designed studies into the non-neurological complications of ischaemic stroke are warranted.

Abbreviations

MODS: Multiple organ dysfunction syndrome; ARDS: Acute respiratory distress syndrome; PBW: Predicted body weight; PEEP: Positive end-expiratory pressure; RM: Recruitment manoeuvres; $\mathrm{FiO}_{2}$ : Fraction of inspired oxygen;

ECG: Electrocardiogram; NIHSS: National Institute of Health Stroke Scale; AKI: Acute kidney injury; OR: Odds ratio; NAFLD: Non-alcoholic fatty acid disease

\section{Acknowledgements}

None

Publication costs

Publication costs are founded by Policlinico San Martino, Genova, Italy.

About the Supplement

About this supplement" information: This article has been published as part of Intensive Care Medicine Experimental Volume 8 Supplement 1, 2020: Proceedings from the Fourth International Symposium on Acute Pulmonary Injury and Translation Research (INSPIRES IV). The full contents of the supplement are available at https://icm-experimental. springeropen.com/articles/supplements/volume-8-supplement-1.

Authors' contributions

CR, DB wrote the manuscript; $C R, D B, C S, P L S, P R M R$, PP designed and revised the manuscript. All authors read and approved the final manuscript.

\section{Funding}

PLS and PRMR are supported by the Brazilian Council for Scientific and Technological Development (CNPq), the Rio de Janeiro State Research Foundation (FAPERJ), and Coordination for the Improvement of Higher Education Personnel (CAPES).

Availability of data and materials

Not applicable

Ethics approval and consent to participate

Not applicable

Consent for publication

not applicable

Competing interests

None

Author details

${ }^{1}$ Anesthesia and Intensive Care, San Martino Policlinico Hospital, IRCCS for Oncology and Neuroscience, Largo Rosanna Benzi 10, 16100 Genoa, Italy. '2Department of Surgical Sciences and Integrated Diagnostics, University of Genoa, Genoa, 
Italy. ${ }^{3}$ Laboratory of Pulmonary Investigation, Carlos Chagas Filho Institute of Biophysics, Federal University of Rio de Janeiro, Rio de Janeiro, Brazil.

Received: 14 July 2020 Accepted: 16 July 2020

Published: 18 December 2020

\section{References}

1. Heuer JF, Selke M, Crozier TA, Pelosi P, Herrmann P, Perske C, Quintel M (2012) Effects of acute intracranial hypertension on extracerebral organs: a randomized experimental study in pigs. J Neurol Surg A Cent Eur Neurosurg 73:289-295

2. Roth GA, Feigin VL, Nguyen G et al (2018) Global, regional, and country-specific lifetime risks of stroke, 1990 and $2016 . \mathrm{N}$ Engl J Med 379:2429-2437

3. Bill O, Zufferey P, Faouzi M, Michel P (2013) Severe stroke: patient profile and predictors of favorable outcome. J Thromb Haemost 11:92-99

4. Yoo AJ, Sheth KN, Kimberly WT et al (2013) Validating imaging biomarkers of cerebral edema in patients with severe ischemic stroke. J Stroke Cerebrovasc Dis 22:742-749

5. Kleiman DA, Barie PS (2014) Survival in fully manifest multiple organ dysfunction syndrome. Surg Infect (Larchmt) 15 445-449

6. Liu HB, Tian J, Zhao JX, Song DB, Tian JK (2008) Study on the clinical epidemiological features of acute cerebral stroke inducing systemic inflammatory response syndrome and multiple organ dysfunction syndrome. Zhonghua Liu Xing Bing Xue Za Zhi 29:294-296

7. Pelosi P, Rocco PRM (2011) The lung and the brain: a dangerous cross-talk. Crit Care 15:168

8. Bai W, Li W, Ning YL et al (2017) Blood glutamate levels are closely related to acute lung injury and prognosis after stroke. Front Neurol 8:755

9. Pelosi P, Severgnini P, Chiaranda M (2005) An integrated approach to prevent and treat respiratory failure in braininjured patients.

10. Chamorro Á, Urra X, Planas AM (2007) Infection after acute ischemic stroke: a manifestation of brain-induced immunodepression. Stroke. Mar 38(3):1097-1103

11. Armstead WM, Vavilala MS (2019) Propranolol protects cerebral autoregulation and reduces hippocampal neuronal cell death through inhibition of interleukin-6 upregulation after traumatic brain injury in pigs. Br J Anaesth. https://doi.org/ 10.1016/j.bja.2019.07.017

12. Davison DL, Terek M, Chawla LS (2012) Neurogenic pulmonary edema. Crit Care 16:212

13. Probasco JC, Chang T, Victor D, Nyquist $P$ (2014) Isolated pulmonary edema without myocardial stunning in brainstem strokes. J Neurol Transl Neurosci 2(1):1040

14. Rincon F, Maltenfort M, Dey S, Ghosh S, Vibbert M, Urtecho J, Jallo J, Ratliff JK, McBride JW, Bell R (2014) The prevalence and impact of mortality of the acute respiratory distress syndrome on admissions of patients with ischemic stroke in the united states. J Intensive Care Med 29:357-364

15. Wartenberg KE, Schmidt JM, Claassen J, Temes RE, Frontera JA, Ostapkovich N, Parra A, Connolly ES, Mayer SA (2006) Impact of medical complications on outcome after subarachnoid hemorrhage. Crit Care Med 34:617-623 quiz 624

16. Austin V, Ku JM, Miller AA, Vlahos R (2019) Ischaemic stroke in mice induces lung inflammation but not acute lung injury. Sci Rep 9:3622

17. Zhao JN, Liu Y, Li HC (2015) Aspiration-related acute respiratory distress syndrome in acute stroke patient. PLoS One. https://doi.org/10.1371/journal.pone.0118682

18. Tejerina E, Pelosi P, Muriel A et al (2017) Association between ventilatory settings and development of acute respiratory distress syndrome in mechanically ventilated patients due to brain injury. J Crit Care 38:341-345

19. Robba C, Bonatti G, Battaglini D et al.(2019). Mechanical ventilation in patients with acute ischaemic stroke: from pathophysiology to clinical practice. Crit Care. 2019 Dec 2;23(1):388

20. Acute Respiratory Distress Syndrome Network, Brower RG, Matthay MA, Morris A, Schoenfeld D, Thompson BT, Wheeler A (2000) Ventilation with lower tidal volumes as compared with traditional tidal volumes for acute lung injury and the acute respiratory distress syndrome. N Engl J Med 342:1301-1308

21. Zhang X, Yang Z, Wang Q, Fan H (2011) Impact of positive end-expiratory pressure on cerebral injury patients with hypoxemia. Am J Emerg Med 29:699-703

22. Rowat AM, Dennis MS, Wardlaw JM (2006) Hypoxaemia in acute stroke is frequent and worsens outcome. Cerebrovasc Dis 21:166-172

23. Jeon SB, Choi HA, Badjatia N, Schmidt JM, Lantigua H, Claassen J, Connolly ES, Mayer SA, Lee K (2014) Hyperoxia may be related to delayed cerebral ischemia and poor outcome after subarachnoid haemorrhage. J Neurol Neurosurg Psychiatry 85:1301-1307

24. Damiani E, Adrario E, Girardis M, Romano R, Pelaia P, Singer M, Donati A (2014) Arterial hyperoxia and mortality in critically ill patients: a systematic review and meta-analysis. Crit Care. https://doi.org/10.1186/s13054-014-0711-x

25. Floyd TF, Clark JM, Gelfand R, Detre JA, Ratcliffe S, Guvakov D, Lambertsen CJ, Eckenhoff RG (2003) Independent cerebral vasoconstrictive effects of hyperoxia and accompanying arterial hypocapnia at 1 ATA. J Appl Physiol 95:24532461

26. Neto AS, Hemmes SNT, Barbas CSV et al (2016) Association between driving pressure and development of postoperative pulmonary complications in patients undergoing mechanical ventilation for general anaesthesia: a metaanalysis of individual patient data. Lancet Respir Med 4:272-280

27. Langhorne P, Stott DJ, Robertson L, MacDonald J, Jones L, McAlpine C, Dick F, Taylor GS, Murray G (2000) Medical complications after stroke: a multicenter study. Stroke 31:1223-1229

28. Hoffmann S, Harms H, Ulm L et al (2017) Stroke-induced immunodepression and dysphagia independently predict stroke-associated pneumonia - the PREDICT study. J Cereb Blood Flow Metab 37:3671-3682

29. Hannawi Y, Hannawi B, Rao CPV, Suarez JI, Bershad EM (2013) Stroke-associated pneumonia: major advances and obstacles stroke-associated pneumonia. Cerebrovasc Dis 35:430-443 
30. Zapata-Arriaza E, Moniche F, Blanca P-G et al (2018) External validation of the ISAN, A2DS2, and AIS-APS scores for predicting stroke-associated pneumonia. J Stroke Cerebrovasc Dis 27:673-676

31. Horan TC, Andrus M, Dudeck MA (2008) CDC/NHSN surveillance definition of health care-associated infection and criteria for specific types of infections in the acute care setting. Am J Infect Control 36:309-332

32. Westendorp WF, Vermeij JD, Zock E et al (2015) The preventive antibiotics in stroke study (PASS): a pragmatic randomised open-label masked endpoint clinical trial. Lancet 385:1519-1526

33. Quilez ME, Fuster G, Villar J, Flores C, Martí-Sistac O, Blanch L, López-Aguilar J (2011) Injurious mechanical ventilation affects neuronal activation in ventilated rats. Crit care 15:R124

34. Samary CS, Ramos AB, Maia LA et al (2018) Focal ischemic stroke leads to lung injury and reduces alveolar macrophage phagocytic capability in rats. Crit Care 22:249

35. Muench E, Bauhuf C, Roth H, Horn P, Phillips M, Marquetant N, Quintel M, Vajkoczy P (2005) Effects of positive endexpiratory pressure on regional cerebral blood flow, intracranial pressure, and brain tissue oxygenation. Crit Care Med 33:2367-2372

36. Mazzeo AT, Fanelli V, Mascia L (2013) Brain-lung crosstalk in critical care: how protective mechanical ventilation can affect the brain homeostasis. Minerva Anestesiol 79:299-309

37. Simonis FD, Serpa Neto A, Binnekade JM et al (2018) Effect of a low vs intermediate tidal volume strategy on ventilatorfree days in intensive care unit patients without ARDS: a randomized clinical trial. JAMA 320:1872-1880

38. Roquilly A, Cinotti $R$, Jaber $S$ et al (2013) Implementation of an evidence-based extubation readiness bundle in 499 brain-injured patients: a before-after evaluation of a quality improvement project. Am J Respir Crit Care Med 188:958966

39. Asehnoune K, Mrozek S, Perrigault PF et al (2017) A multi-faceted strategy to reduce ventilation-associated mortality in brain-injured patients. The BI-VILI project: a nationwide quality improvement project. Intensive Care Med 43:957-970

40. Mascia L, Grasso S, Fiore T, Bruno F, Berardino M, Ducati A (2005) Cerebro-pulmonary interactions during the application of low levels of positive end-expiratory pressure. Intensive Care Med 31:373-379

41. Georgiadis D, Schwarz S, Baumgartner RW, Veltkamp R, Schwab S (2001) Influence of positive end-expiratory pressure on intracranial pressure and cerebral perfusion pressure in patients with acute stroke. Stroke 26:174-181

42. Lowe GJ, Ferguson ND (2006) Lung-protective ventilation in neurosurgical patients. Curr Opin Crit Care 12(1):3-7

43. Schnabel RB, Haeusler KG, Healey JS et al.(2019). Searching for atrial fibrillation poststroke: a white paper of the AFSCREEN International Collaboration.Circulation. Nov 26;140(22):1834-1850.

44. Cheshire WP Jr, Saper CB (2006) The insular cortex and cardiac response to stroke. Neurology 66:1296-1297

45. Iadecola C, Anrather J (2011) The immunology of stroke: from mechanisms to translation. Nat Med 17:796-808

46. Silvani A, Calandra-Buonaura G, Dampney RAL, Cortelli P (2016) Brain-heart interactions: physiology and clinical implications. Philos. Trans. A. Math. Phys. Eng. Sci. 374

47. Barugh AJ, Gray P, Shenkin SD, MacLullich AMJ, Mead GE (2014) Cortisol levels and the severity and outcomes of acute stroke: a systematic review. J Neurol 261:533-545

48. Braniste V, Al-Asmakh M, Kowal C et al (2014) The gut microbiota influences blood-brain barrier permeability in mice. Sci Transl Med 6:263ra158

49. Chimowitz Ml, Mancini GB (1992) Asymptomatic coronary artery disease in patients with stroke. Prevalence, prognosis, diagnosis, and treatment. Stroke 23:433-436

50. Finsterer J, Wahbi K (2014) CNS-disease affecting the heart: brain-heart disorders. J Neurol Sci 345:8-14

51. Prosser J, MacGregor L, Lees KR, Diener HC, Hacke W, Davis S (2007) Predictors of early cardiac morbidity and mortality after ischemic stroke. Stroke 38:2295-2302

52. Yoshimura S, Toyoda K, Ohara T, Nagasawa H, Ohtani N, Kuwashiro T, Naritomi H, Minematsu K (2008) Takotsubo cardiomyopathy in acute ischemic stroke. Ann Neurol 64:547-554

53. Rauh G, Fischereder M, Spengel FA (1996) Transesophageal echocardiography in patients with focal cerebral ischemia of unknown cause. Stroke 27:691-694

54. Simula S, Muuronen AT, Taina M, Jäkälä P, Sipola P, Vanninen R, Hedman M (2014) Effect of middle cerebral artery territory ischemic stroke on QT interval. J Stroke Cerebrovasc Dis 23:717-723

55. Lavy S, Yaar I, Melamed E, Stern S (1974) The effect of acute stroke on cardiac functions as observed in an intensive stroke care unit. Stroke 5:775-780

56. Lee M, Ovbiagele B, Hong KS, Wu YL, Lee JE, Rao NM, Feng W, Saver JL (2015) Effect of blood pressure lowering in early ischemic stroke: meta-analysis. Stroke 46:1883-1889

57. Katsanos AH, Korantzopoulos P, Tsivgoulis G, Kyritsis AP, Kosmidou M, Giannopoulos S (2013) Electrocardiographic abnormalities and cardiac arrhythmias in structural brain lesions. Int J Cardiol 167:328-334

58. Oppenheimer S (2006) Cerebrogenic cardiac arrhythmias: cortical lateralization and clinical significance Stephen Oppenheimer. Clin Auton Res 16:6-11

59. Daniele O, Caravaglios G, Fierro B, Natalè E (2002) Stroke and cardiac arrhythmias. J Stroke Cerebrovasc Dis 11:28-33

60. Dimant J, Grob D (1977) Electrocardiographic changes and myocardial damage in patients with acute cerebrovascular accidents. Stroke. 8(4):448-55

61. Gunnoo T, Hasan N, Khan MS, Slark J, Bentley P, Sharma P (2016) Quantifying the risk of heart disease following acute ischaemic stroke: a meta-analysis of over 50,000 participants. BMJ Open 6:e009535

62. Touzé E, Varenne O, Chatellier G, Peyrard S, Rothwell PM, Mas JL (2005) Risk of myocardial infarction and vascular death after transient ischemic attack and ischemic stroke: a systematic review and meta-analysis. Stroke 36:2748-2755

63. Ali A, Ahmad MQ, Malik MB et al (2018) Neurogenic stunned myocardium: a literature review. Cureus. https://doi.org/10. 7759/cureus.3129

64. Masci A, Barone L, Dedè L, Fedele M, Tomasi C, Quarteroni A, Corsi C (2019) The impact of left atrium appendage morphology on stroke risk assessment in atrial fibrillation: a computational fluid dynamics study. Front Physiol. https:// doi.org/10.3389/fphys.2018.01938

65. Fonseca AC, Alves P, Inácio N, Marto JP, Viana-Baptista M, Pinho-E-Melo T, Ferro JM, Almeida AG (2018) Patients with undetermined stroke have increased atrial fibrosis: a cardiac magnetic resonance imaging study. Stroke 49:734-737 
66. Bieber M, Werner RA, Tanai E et al (2017) Stroke-induced chronic systolic dysfunction driven by sympathetic overactivity. Ann Neurol 82:729-743

67. Kuznetsova T, Herbots L, López B et al (2009) Prevalence of left ventricular diastolic dysfunction in a general population. Circ Heart Fail 2:105-112

68. Park HK, Kim BJ, Yoon CH, Yang MH, Han MK, Bae HJ (2016) Left ventricular diastolic dysfunction in ischemic stroke: functional and vascular outcomes. J Stroke 18:195-202

69. Smith M, Reddy U, Robba C, Sharma D, Citerio G (2019) Acute ischaemic stroke: challenges for the intensivist. Intensive Care Med 45:1177-1189

70. Colivicchi F, Bassi A, Santini M, Caltagirone C (2005) Prognostic implications of right-sided insular damage, cardiac autonomic derangement, and arrhythmias after acute ischemic stroke. Stroke 36:1710-1715

71. Monnet X, Teboul JL (2017) Transpulmonary thermodilution: advantages and limits. Crit Care. https://doi.org/10.1186/ s13054-017-1739-5

72. Powers WJ, Rabinstein AA, Ackerson T et al (2018) 2018 Guidelines for the early management of patients with acute ischemic stroke: a guideline for healthcare professionals from the American Heart Association/American Stroke Association. Stroke 49(3):e46-e110

73. Ibrahim MS, Samuel B, Mohamed W, Suchdev K (2019) Cardiac dysfunction in neurocritical care: an autonomic perspective. Neurocrit Care 30:508-521

74. Arnold J, Ng KP, Sims D, Gill P, Cockwell P, Ferro C (2018) Incidence and impact on outcomes of acute kidney injury after a stroke: a systematic review and meta-analysis. BMC Nephrol 19:283

75. Singbartl K, Kellum JA (2012) AKI in the ICU: definition, epidemiology, risk stratification, and outcomes. Kidney Int 81: 819-825

76. Toyoda K, Ninomiya T (2014) Stroke and cerebrovascular diseases in patients with chronic kidney disease. Lancet Neurol 13:823-833

77. Yates RB, Sheng H, Sakai H, Kleven DT, DeSimone NA, Stafford-Smith M, Warner DS (2013) Lack of evidence for a remote effect of renal ischemia/reperfusion acute kidney injury on outcome from temporary focal cerebral ischemia in the rat. J Cardiothorac Vasc Anesth 27:71-78

78. Hénaut L, Grissi M, Brazier F et al (2019) Cellular and molecular mechanisms associated with ischemic stroke severity in female mice with chronic kidney disease. Sci Rep 9:6432

79. Kumai Y, Kamouchi M, Hata J, Ago T, Kitayama J, Nakane H, Sugimori H, Kitazono T, Investigators FSR (2012) Proteinuria and clinical outcomes after ischemic stroke. Neurology 78:1909-1915

80. Kuwashiro T, Sugimori H, Ago T, Kamouchi M, Kitazono T, Investigators FSR (2012) Risk factors predisposing to stroke recurrence within one year of non-cardioembolic stroke onset: the Fukuoka Stroke Registry. Cerebrovasc Dis 33:141-149

81. Rodríguez-Yáñez M, Castellanos M, Blanco M et al (2006) Micro- and macroalbuminuria predict hemorrhagic transformation in acute ischemic stroke. Neurology 67:1172-1177

82. Cutting S, Castro C, Lee VH, Prabhakaran S (2014) Impaired renal function is not associated with increased volume of intracerebral hemorrhage. J Stroke Cerebrovasc Dis 23:86-90

83. Hao Z, Wu B, Lin S, Kong FY, Tao WD, Wang DR, Liu M (2010) Association between renal function and clinical outcome in patients with acute stroke. Eur Neurol 63:237-242

84. Alexander KS, Zakai NA, Lidofsky SD, Callas PW, Judd SE, Tracy RP, Cushman M (2018) Non-alcoholic fatty liver disease, liver biomarkers and stroke risk: the reasons for geographic and racial differences in stroke cohort. PLoS One 13: e0194153

85. Henrion J, Schapira M, Luwaert R, Colin L, Delannoy A, Heller FR (2003) Hypoxic hepatitis: clinical and hemodynamic study in 142 consecutive cases. Medicine (Baltimore) 82:392-406

86. Bondanelli M, Ambrosio MR, Onofri A, Bergonzoni A, Lavezzi S, Zatelli MC, Valle D, Basaglia N, Degli Uberti EC (2006) Predictive value of circulating insulin-like growth factor I levels in ischemic stroke outcome. J Clin Endocrinol Metab 91: 3928-3934

87. Bondanelli M, Ambrosio MR, Carli A, Bergonzoni A, Bertocchi A, Zatelli MC, Ceruti S, Valle D, Basaglia N, degli Uberti EC (2010) Predictors of pituitary dysfunction in patients surviving ischemic stroke. J Clin Endocrinol Metab 95:4660-4668

88. Wahab NA, Razak NZA, Sukor N, Zainudin S, Razali AM, Mustafa N, Wan Yahya WNN, Kamaruddin NA (2015) Relative adrenal insufficiency amongst hospitalized mild to moderate acute ischemic stroke patients. Arch Iran Med 18:89-93

\section{Publisher's Note}

Springer Nature remains neutral with regard to jurisdictional claims in published maps and institutional affiliations.

\section{Submit your manuscript to a SpringerOpen ${ }^{\circ}$ journal and benefit from:}

- Convenient online submission

- Rigorous peer review

- Open access: articles freely available online

High visibility within the field

- Retaining the copyright to your article

Submit your next manuscript at $\boldsymbol{\nabla}$ springeropen.com 